\title{
AC 2008-230: ENSURING A STRONG U.S. ENGINEERING WORKFORCE FOR TECHNOLOGY INNOVATION AND COMPETITIVENESS: A PARTNERSHIP BETWEEN ACADEMIA AND INDUSTRY
}

\section{Donald Keating, University of South Carolina}

DONALD A. KEATING is professor emeritus, mechanical engineering, College of Engineering, University of South Carolina, past chair of the Graduate Studies Division, and chair of the National Collaborative Task Force

Thomas Stanford, University of South Carolina THOMAS G. STANFORD is assistant professor of Chemical Engineering, University of South Carolina

Joseph J. Rencis, University of Arkansas JOSEPH J. RENCIS is professor, head, and the 21 st century leadership chair in engineering, Department of Mechanical Engineering, University of Arkansas

\section{Eugene DeLoatch, Morgan State University}

EUGENE M. DeLOATCH is dean, School of Engineering, Morgan State University, and a past president of the American Society of Engineering Education

\section{Mohammad Noori, North Carolina State University} MOHAMAD NOORI is dean, College of Engineering, California State Polytechnic University, and secretary/treasurer Graduate Studies Division

\section{Edward Sullivan, California Polytechnic State University}

EDWARD SULLIVAN is associate dean and professor of Civil Engineering, College of Engineering, California State Polytechnic University

David Woodall, Oregon Institute of Technology

DAVID WOODALL is provost, Oregon Institute of Technology, past chair Engineering Research Council

\section{Norman Egbert, Rolls-Royce Corporation}

NORMAN F. EGBERT is vice president, Engineering and Technology, Rolls-Royce Corporation

\section{David Quick, Rolls-Royce Corporation}

DAVID H. QUICK is manager, R\&D customer requirements, R\&T Strategy, Liberty Works, Rolls-Royce North American Technologies, and past chair Corporate Members Council, and past chair of the College Industry Partnership Division of the American Society for Engineering Education

\section{Roger Olson, Rolls-Royce Corporation}

ROGER N. OLSON is lead stress analysis engineer, Rolls-Royce Corporation, and a director of the College Industry Partnership Division of the American Society for Engineering Education

\section{Samuel Truesdale, Rolls-Royce Corporation}

SAMUEL L. TRUESDALE is manager of employee development, engineering business improvement organization, Rolls-Royce Corporation, and chair, College Industry Partnership Division of the American Society for Engineering Education 
Albert McHenry, Arizona State University

ALBERT L. Mc HENRY is provost and vice president, Arizona State University Polytechnic, and former vice president of public affairs of the American Society for Engineering Education

Timothy Lindquist, Arizona State University

TIMOTHY LINDQUIST is interim dean, College of Technology and Innovation, Arizona State University Polytechnic

Joseph Tidwell , Arizona State University Polytechnic

JOSEPH P. TIDWELL is director, of the joint alliance of companies managing education for technology JACMET, and community liaison, College of Technology and Innovation, Arizona State University Polytechnic, and past chair College Industry Partnership Division of the American Society for Engineering Education

Harvey Palmer, Rochester Institute of Technology

HARVEY PALMER is dean, Kate Gleason College of Engineering, Rochester Institute of Technology

Mark Smith, Rochester Institute of Technology

MARK SMITH is director, product development \& manufacturing leadership program, of the Kate Gleason college of engineering, Rochester Institute of Technology

Duane Dunlap, Purdue University

DUANE D. DUNLAP is professor and associate dean, College of Technology, Purdue

University, and chair of the Graduate Studies Division of the American Society for Engineering Education

Mark Schuver, Purdue University

MARK SCHUVER is director of professional education, College of Technology, Purdue University

Edmund Segner, University of Alabama at Birmingham

EDMUND SEGNER is chair emeritus of civil engineering, University of Alabama at Birmingham and representative to the National Collaborative from the education committee of the National Society of Professional Engineers (NSPE)

Barry Farbrother, University of New Haven

BARRY FARBROTHER is dean, Tagliatela College of Engineering, University of New Haven

Stephen Tricamo, New Jersey Institute of Technology

STEPHEN J. TRICAMO is professor of Industrial and Manufacturing Engineering, and former dean, College of Engineering and Technology, New Jersey Institute of Technology

Ken Burbank, Western Carolina University

KEN BURBANK is professor and Department Head, Department of Engineering and

Technology, Western Carolina University

Carla Purdy, University of Cincinnati

CARLA PURDY is associate professor, University of Cincinnati, and program chair, Graduate 
Studies Division, American Society of Engineering Education

\section{Randall Holmes, Caterpillar Inc.}

RANDALL J. HOLMES is Workforce Development Manager, DPP Human Resources, Caterpillar Inc. 


\title{
Ensuring a Strong U.S. Engineering Workforce for Technology Innovation and Competitiveness: A Partnership between Academia and Industry
}

\author{
Engineering is a creative profession, concerned with the combining of human, \\ material, and economic resources to meet the needs of society ... for the \\ advancement and betterment of human welfare. \\ National Collaborative Task Force on Engineering \\ Graduate Education Reform - 2008
}

\section{Introduction}

This is the first of four invited papers prepared for the special session of the National Collaborative Task Force on Engineering Graduate Education Reform. This paper presents an overview of the National Collaborative initiative, its purpose, and the unique partnership that is occurring between academia and industry in advancing professional graduate engineering education for engineering practice in order to strengthen the innovative capacity of the U.S. Engineering Workforce in industry for world-class competitiveness and national security purposes.

\section{Strengthening U.S. Engineering Education for Competitiveness}

Today, as never before, America's future technological competitiveness will depend largely on our ability to innovate and to revitalize the core capacity for continuous innovation within the U.S. Engineering Workforce in America's industry. ${ }^{1}$ Innovation ... as the Council on Competitiveness points out ... "will be the single most important factor in determining America's success through the $21^{\text {st }}$ century."

To compete ... America must innovate.

Consequently, as the National Academies' report, Rising above the Gathering Storm, recommends, we must "ensure that the United States is the premier place in the world to innovate." 3

\subsection{Statement of the Problem}

But a disturbing reality is now apparent that must be corrected. Over the last several decades, 1960's, 70's, 80's, 90's, the nation has invested wisely, because of 1945 U.S. science policy in fostering world preeminence of research-oriented graduate education for the U.S. Scientific Workforce for basic research and 'discovery' at the universities, and must continue to do so. ${ }^{4}$ But it has not made a parallel investment and balanced educational emphasis during this same time period in fostering professionally-oriented graduate education, beyond entry level engineering, that supports the further development of the U.S. Engineering Workforce in industry - which is the nation's primary engineering resource and creative wellspring for the generation, development and innovation of U.S. technology for competitiveness.

\subsection{What is the Problem that We Want to Fix ?}

Although the United States has led the world in basic research and research-based graduate education for the nation's scientific workforce at the universities for 'discovery', inquiry and scientific investigation, the National Collaborative Task Force concludes that research-based graduate education does not meet the full spectrum of professional educational needs of the engineer and engineering leader in industry nor does it reflect the modern practice of engineering and the engineering method for 
the deliberate generation, development, and innovation of new, improved, and breakthrough technology [See Appendix A, B].

One size graduate education doesn't fit all.

Excellence in basic research and excellence in engineering practice for world-class technology development \& innovation are two very different pursuits with different purposes and methods; requiring two different types of education at the graduate level.

The National Collaborative is focusing on two primary questions:

- First, can an effective system of professionally-oriented engineering graduate education be created in the United States for further developing the nation's engineering talent beyond entry-level in industry, focusing on the creative practice of engineering for innovation, so that the continuing future of engineering practice for creative technology development $\&$ innovation in this country may be assured for economic competitiveness and national security purposes?

- Second, how can this system of advanced professional engineering graduate education be implemented across the United States using the combined resources of universities and industry to ensure world-class engineering leadership for innovation so that each state and region can prosper over the long-term?

\subsection{Why Do We want to Fix the Problem?}

Lack of a coherent system of professional graduate engineering education - that advances the further graduate growth and development of the nation's engineers relevant to the creative practice of engineering for innovation - has been a contributing factor to long-term underdevelopment of our nation's engineering potential for innovation during the past decades which threatens long-term U.S. competitiveness.

Whereas undergraduate engineering education adequately prepares the young engineering graduate for entry into the practice of engineering at the first level of engineering [ABET], it does not prepare, nor is it intended to prepare, our nation's engineers for leadership at all levels of practice. There are nine progressive growth levels of leadership responsibility in engineering, necessitating further skills-sets development beyond entry level engineering. ${ }^{5,6}$

As the National Academy's Committee on Science, Engineering, and Public Policy (COSEPUP) report [Reshaping the Graduate Education of Scientists and Engineers] pointed out in 1995, science and engineering graduate education has evolved during the last four decades on university campuses in the United States primarily as research-oriented, largely as an outgrowth of 1945 U.S. science policy for basic research. However, graduate engineering education must be devised also for those professionals in engineering who are pursuing non-research type careers. ${ }^{7}$

But, key to improving the graduate professional educational process in engineering for technological innovation is the realization that the modern practice of engineering for technology development \& innovation 'has itself changed substantially' from that portrayed by linear research-driven paradigm of engineering practice of 1945 U.S. science policy (See Appendix A). Yet, with notable exceptions, the mainstream of U.S. engineering graduate education still has not reflected this change. 
The National Collaborative concludes also that the education of the engineer is not simply a one-time event of 4, 5, or 8 year duration. As the ASEE-Green Report [Engineering Education for a Changing World $]$ has pointed out, an engineer's education is a lifelong learning and growth process. ${ }^{8}$

However, with notable exceptions, U.S. engineering education for practice remains constrained primarily to the undergraduate level on too many campuses. To make the opportunity of high-quality professional engineering graduate education for 'lifelong learning' more wide-spread across the country, the National Collaborative Task Force believes that professional graduate education of engineers, at the advanced level, must be integrative with and enable positive growth of the engineer for the practice of engineering throughout the engineer's entire professional career of creative practice.

As the 1974 National Science Foundation report [Workshop on Continuing Education for Engineers at Mid-Career] pointed out as early as 1974 - "Coursework has not been designed which correlates well with the professional growth of engineers, either as technical specialists or as managers ... Selection of educational experiences generally relies on the individual engineer's selection from a 'cafeteria' of study opportunities." ${ }^{9}$ Unfortunately, this statement is still much too prevalent across the nation.

As a long-term consequence, the 'creative, innovative, and leadership potential' of the U.S. engineering workforce in industry has become one of the nation's most 'underdeveloped human resources' in the country for leading edge creative engineering practice for innovation at the resulting expense of our nation's decline in competitiveness.

\subsection{Why Do We Want to Fix the Problem Now?}

Revitalizing our country's capacity for technological innovation is linked directly to how creative and innovative our U.S. Engineering Workforce in industry is and how we sustain the progressive development of this vital asset.

Developing a highly innovative U.S. Engineering Workforce in industry, capable of applying the engineering abilities of creative problem-solving as 'champions, innovators, and leaders' thereby generating new technology to meet real-world needs is crucial to the future success of U.S. technological innovation.

The U.S. Engineering Workforce in industry is one of the nation's most vital and potential creative assets in sustaining our economic development, national security, improvement in the quality of life, and wellbeing as a nation.

As the Council on Competitiveness points out - "The Council's business leaders agree that every company's most important asset are the people who walk in its doors every morning ... Talented people creating new ideas and innovative technologies keep the economy strong, and growing stronger ... The education and training that spark Americans' creativity and give them cutting-edge skills are a key to competitiveness." 10

\subsection{Creating Competitive Advantage - Through Advancement of Professional Graduate Engineering Education for U.S. Engineers in Industry}

The National Collaborative Task Force believes that we, as a nation, can create a stronger American competitive advantage, both immediately and over the long-term, by reversing the status quo of U.S. engineering graduate education through a focused and 'bold initiative' in engineering graduate education specifically designed in partnership with industry to enable the further, positive growth and professional 
development of the nation's engineers for innovation throughout the engineer's entire professional career of creative engineering practice.

As Whitfield, recognized as early as $1972-$

"It is taken as self-evident that the creative output of [any nation's] engineering will be raised quickest and over the widest area by successful efforts to improve the creativity of the engineer already in industry, specifically the engineer who has added and adequacy of experience to his [or her] basic technical training." 11

\section{Project Description - Workforce Development in Engineering for Innovation}

Deliberately created in 2000 - by the ASEE-Graduate Studies Division, Corporate Members Council, the College Industry Partnership Division and leaders from industry and universities across the nation, the National Collaborative Task Force on Engineering Graduate Education Reform is embarking on a major initiative to make this much needed advancement in professional engineering graduate education actually happen in the national interest.

\subsection{Fixing the Problem}

While U.S. engineering education is not in crisis at the undergraduate level, it never the less has not attained its potential in formulating a system that facilitates the fullest 'creative, innovative, and leadership' development at the graduate level for the nation's engineers who actually practice engineering in industry.

This underdevelopment of the nation's engineering strength for innovation is placing a crisis in U.S. competitiveness. America's decline in competitiveness can be reversed through investment in the professional education of our engineering workforce. Accordingly, America's competitive edge in leading the world in engineering and technological innovation depends in turn upon the U.S. system of engineering graduate education to support the further graduate development of our creative engineering talent for innovation.

But the change that we are talking about is much more than describing in detail the assembly of existing courses, curricula, or educational programs that already exist across the country. Rather, the National Collaborative Task Force is taking a deliberate planned, engineering systems approach to the situation in order to re-engineer a professional component of graduate engineering education, that is professionallyoriented, practice-centered, and focused on accelerating innovation in industry, specifically designed to meet the progressive needs, skill-sets, and responsibilities of upward mobile engineers who are pursuing engineering and engineering leadership careers directly relevant to the practice of engineering.

\subsection{The Power of Collaboration in the Advancement of Professional Engineering Education in the National Interest}

Although 'bits and pieces' of this educational advancement have already been attained in piecemeal fashion across the county, these components have not been integrated as a system for replication across the nation in the national interest nor have they been developed to their fullest in meeting the needs of the practicing engineer and engineering leader in industry.

The National Collaborative welcomes a diversity of education approaches and methods in the coalition but within a common framework of goals and objectives. Yet the National Collaborative is mindful that 
each university participant in this effort must focus in the national interest and engage in shared common purpose for this educational advancement to flourish. Toward this aim, each participating university has 'something to contribute to the other' - and to learn from the other in common cause - thereby going beyond their own self-institutional interests to the point where the resulting combined effects in national enhancement of the U.S. Engineering Workforce infrastructure for innovation are significantly greater than could ever occur by institutions working alone.

\subsection{Overall Purpose and Outcomes of the Initiative}

The National Collaborative Task Force will identify the progressive needs, attributes, and responsibilities required of the engineer in practice. Based on this analysis, the Task Force will next design and implement a new model of advanced professional graduate education for the nation's engineers in industry that fosters 'lifelong learning' and professionally-oriented, practice-centered engineering graduate education that supports:

- All nine levels of engineering practice for the purposeful generation, development, and innovation of useful technology for competitive advantage to the engineer's company or to meet meaningful societal needs - from the beginning growth levels of entry-level engineering at project level through the senior engineering growth levels of chief engineer responsible for corporate technology policy making, leadership and execution.

- The modern paradigm of the practice of engineering for the systematic and continuous generation, development, and innovation of new / improved / breakthrough technology for products, processes, systems and operations through the professional Masters, Doctoral, and Engineer Fellow levels of engineering leadership for innovation.

- The learning and creative process by which experienced engineers learn, grow, and develop as reflective practitioners - from novice to competent engineer, to expert engineer, and to expert engineering leader for new technology development $\&$ innovation.

- The professional educational process of practice-centered, project-based learning for meaningful engineering works emphasizing not only advanced studies, experiential-based learning, and selfdirected learning but also 'learning by doing' during the creative practice of engineering itself.

\subsection{Specific Goals and Objectives}

The initiative will be accomplished in four primary phases.

The Goals of the initiative include the following [ See appendix G]:

\section{- PHASE I - FULL CONCEPT DEVELOPMENT [Years 1 \& 2 ]}

GOAL 1: To create an innovative model of professional graduate engineering education that is integrative with the practice of engineering, fosters lifelong learning, and enables further growth of engineers beyond entry level in industry for increasing leadership responsibility of technology development \& innovation to ensure U.S. technological leadership for competitiveness and national security purposes 


\section{- PHASE II - FULL CONCEPT IMPLEMENTATION [Years 3 \& 4 ]}

GOAL 2: To establish Graduate Centers for Advanced Studies in Engineering Leadership, Technology Innovation, and Policy as a National Demonstration Project for pilot implementation across the country

\section{- PHASE III - FULL CONCEPT IMPROVEMENT \& SUSTAINABILITY [Year 5 ]}

GOAL 3: To assess needs for continuous operational improvement; and to continuously upgrade professional graduate education programs at all levels, the educational processes, the development of faculty, the organizational infrastructure for innovation, and relations with industry to meet these needs.

\section{- PHASE IV - FULL CONCEPT REPLICATION ACROSS THE UNITED STATES}

GOAL 4: To replicate the innovative Graduate Centers in all 50 states across the country in order to accelerate the development of the U.S. engineering workforce for U.S. preeminence in technological innovation to enhance economic competitiveness and national security using the combined formidable strengths of industry and regional universities that will be second to none

\section{Time for Action - Securing America's Leadership in Engineering}

Ultimately our future technological capability, as a nation, depends on sustaining the innovative capacity of our engineering workforce in industry; so the development of our nation's talented engineers and engineering leaders must rise to a national priority in order to regain our competitive advantage.

\subsection{A New Era for U.S. Engineering Innovation}

Today, a new era for U.S. engineering innovation is evolving and the National Collaborative initiative is addressing the higher educational issues required for the United States to sustain its preeminence in innovative engineering in America's industry.

As Hill has pointed out:

"Networks of highly creative individuals and collaborating firms will devise and produce complex new systems that meet human needs in unexpectedly new and responsive ways ...... Simply redoubling our efforts to fund more research and to prepare more scientists and engineers along the models of the past is unlikely to be sufficient to meet the new needs ... Contrary to the consensus embodied in the America COMPETES Act, it is not so much that we need more scientists and engineers but that we need new kinds of scientists and engineers." 12

More of the same in engineering education or redoubling efforts in basic research is insufficient to meet the innovative challenge to regain America's competitive advantage. It is time to recognize that change in engineering education is required and that more of the same is not the answer. 
The paradigm of the modern practice of engineering for the deliberate, systematic, and purposeful creation, development, and innovation of new needed technology to meet real-world needs in the global economy has changed substantially from a model no longer relevant.

What we need to do is to is to restructure a new type of professional graduate engineering education that models the process of engineering innovation itself and how we want the nation's engineers to develop as leaders of innovation. Not only has the paradigm of engineering itself changed, but so has the manner by which engineers grow in the totality of engineering practice. As Orsak, dean of engineering at Southern Methodist University, has pointed out: "Universities have been slow in recognizing and addressing the shift of the engineer from technical expert to technical leaders ... today, engineers are not only innovating new products but, more important, also leading the companies that build and sell these products."13

The National Collaborative Task Force concludes that the time for action - in revitalizing our nation's competitiveness through sound educational advancement that strengthens the graduate development of the U.S. engineering workforce for world-class technological innovation in industry - is now.

\subsection{Going Beyond Writing Papers}

While it reports periodically to ASEE on its progress, the National Collaborative Task Force is going beyond the limits of just writing papers. It is actually implementing the reform and transforming engineering graduate education to meet the graduate needs of the practicing profession. Yet, it is unrealistic to believe that this advancement will occur overnight or by universities working alone without the support of government or the practicing profession in industry to champion this initiative.

As the Business-Higher Education Forum has pointed out in its 2003 report, Building A Nation Of Learners: "Change cannot happen in a vacuum. An undertaking of this magnitude can happen only through committed leadership with vision and purpose at the highest level. To meet these goals by 2010, federal leaders must rise to this challenge, refocusing existing education and training efforts, and creating the new policies, priorities, and programs that will transform the United States into a nation of learners."14

The initiative, we are embarking on in U.S. engineering education reform, calls for nothing less.

\subsection{Action for Implementing the Change: Taking It Up a Notch to Add the Advancement in Professional Engineering Graduate Education to the Existing System}

In order to initiate full development and implementation of the concept [which has already been proven in piecemeal fashion at different universities across the nation] the National Collaborative Task Force is taking this advancement in engineering education to the next level of excellence.

As Whitfield has pointed out as early as $1972-$

"For innovation to be valued it must be seen to be desirable by those who shape the environment: the government, industrial management, the universities and the engineering institutions who define what an engineer should be. Only when innovation - not just bright ideas, but novel concepts embodied in practice - is really wanted by those in power, will there be any significant move to stimulate and encourage it. Not only must they want it, but they must also be prepared to share the hazards which innovation and the climate for innovation will bring. When such commitment is shown, when key figures in authority are prepare to nail their colours to the mast and give a lead, then lesser men will follow." 15 


\section{Conclusions - An Initiative for Moving Forward}

The National Collaborative has gained the support of leaders from industry and universities across the country for this major advancement. The impact of strengthening the national innovation system through planned advancement of engineering professional graduate education is significant, yielding far reaching effects across every state in the nation. This is a bold initiative and exciting advancement in partnering professionally-oriented graduate education with the practicing engineering profession in America's industry that will stimulate significant regional innovation, new technology developments, and economic growth across the country.

\section{Bibliography}

1. ASEE-Prism, Last Word, November 2007.

2. Council on Competitiveness, Innovate America, 2005.

3. National Academies, Rising Above the Gathering Storm: Energizing and Employing America for a Brighter Economic Future, National Academy Press, 2006.

4. Bush, V., Science: The Endless Frontier, 1945.

5. National Society of Professional Engineers, NSPE Levels of Engineering Responsibility, 2008.

6. American Society of Civil Engineers, ASCE Guidelines for Engineering Grades, 2008.

7. Committee on Science, Engineering, and Public Policy (COSEPUP), Reshaping the Graduate Education of Scientists and Engineers, National Academy Press, 1995.

8. ASEE, Green Report: Engineering Education for a Changing World, American Society for Engineering Education, 1994.

9. Baldwin et al., NSF-Workshop on Continuing Education for Engineers at Mid-career, 1974.

10. Council on Competitiveness, World Class Workforce: Workforce Development, www.compete.org, 2008.

11. Gregory, S.A. [Editor], Creativity and Innovation in Engineering, London Butterworth, 1972.

12. Hill, C.T., Issues in Science and Technology, National Academies, Fall 2007.

13. Orsak, G.C., Engineers: The New Leadership Class, Electronic Business, February 2008.

14. Business-Higher Education Forum, Building a Nation of Learners, 2003.

15. Ibid.

16. Business Roundtable, Tapping America's Potential: The Education for Innovation Initiative, July 2005.

17. National Academy of Engineering, Technically Speaking, 2002.

18. National Academy of Engineering, Educating the Engineer of 2020: Phase I Report, 2004.

19. National Academy of Engineering, Educating the Engineer of 2020: Phase II Report, 2005. 


\begin{abstract}
Appendix A
The Modern Paradigm of the Practice of Engineering for Creative Technology Development \& Innovation Responsive to Real-World Needs of Industry and Society
\end{abstract}

\title{
Needs $\Rightarrow$ Engineering $\Rightarrow$ Technology $\downarrow \uparrow$
}

Directed Basic Scientific Research to gain a better understanding of natural phenomena when needed or anticipated during the technology development project 


\section{Appendix B}

\section{The Modern Paradigm of the Practice of Engineering and Technology Readiness Levels of New Technology for Real-World Needs of Industry and Society}

\section{Technology Readiness Level (TRL)}

\begin{tabular}{l|ll} 
& 10 & \multicolumn{1}{c}{$\begin{array}{c}\text { General Description } \\
\text { Continual Improvement of } \\
\text { System in Service }\end{array}$} \\
Actual System Operationally \\
Proven in Service
\end{tabular}

TRL = Technology Readiness Level 


\section{Appendix C}

\section{Stages of Professional Growth and Responsibilities in the Practice of Engineering for Responsible Leadership of Technology Development \& Innovation}

\section{Stages of Growth \\ ENGINEER IX}

ENGINEER VIII

ENGINEER VII

ENGINEER VI

ENGINEER V

ENGINEER IV

ENGINEER III

ENGINEER I/II

(Entry Level Engineer)

\section{Typical Responsibilities-Autonomy-Judgment}

An engineer-leader at this level is in responsible charge of programs so extensive and complex as to require staff and resources of sizeable magnitude to meet the overall engineering objectives of the organization.

An engineer-leader at this level demonstrates a high degree of creativity, foresight, and mature judgment in planning, organizing, and guiding extensive engineering programs and activities of outstanding novelty and importance. Is responsible for deciding the kind and extent of engineering and related programs needed for accomplishing the objectives of the organization.

In a leadership capacity, is responsible for an important segment of the engineering program of an organization with extensive and diversified engineering requirements. The overall engineering program contains critical problems, the solutions of which require major technological advances and opens the way for extensive related development.

In a leadership capacity, plans, develops, coordinates, and directs a number of large and important projects or a project of major scope and importance. Or, as a senior engineer, conceives, plans, and conducts development in problem areas of considerable scope and complexity. The problems are difficult to define and unprecedented. This involves exploration of subject area, definition of scope, and selection of important problems for development.

In a leadership capacity, plans, develops, coordinates, and directs a large and important project or a number of small projects with many complex features. Or, as an individual principle engineer, carries out complex or novel assignments requiring the development of new or improved techniques and procedures. Work is expected to result in the development of new or refined equipment, materials, processes, or products. Technical judgment knowledge, and expertise for this level usually result from progressive experience.

Plans, schedules, conducts, or coordinates detailed phases of engineering work in part of a major project or in a total project of moderate scope. Fully competent engineer in all conventional aspects of the subject matter of the functional areas of assignments. Devises new approaches to problems encountered. Independently performs most assignments requiring technical judgment.

Performs work that involves conventional types of plans, investigations, or equipment with relatively few complex features for which there are precedents. Requires knowledge of principle and techniques commonly employed in the specific narrow areas of assignments.

Requires knowledge and application of known laws and data. Using prescribed methods, applies standard practices/techniques under direction of an experienced Engineer. 


\section{Appendix D}

Demographics of Creative Potential of the U.S. Engineering Workforce for Technology Development \& Innovation Across the United States

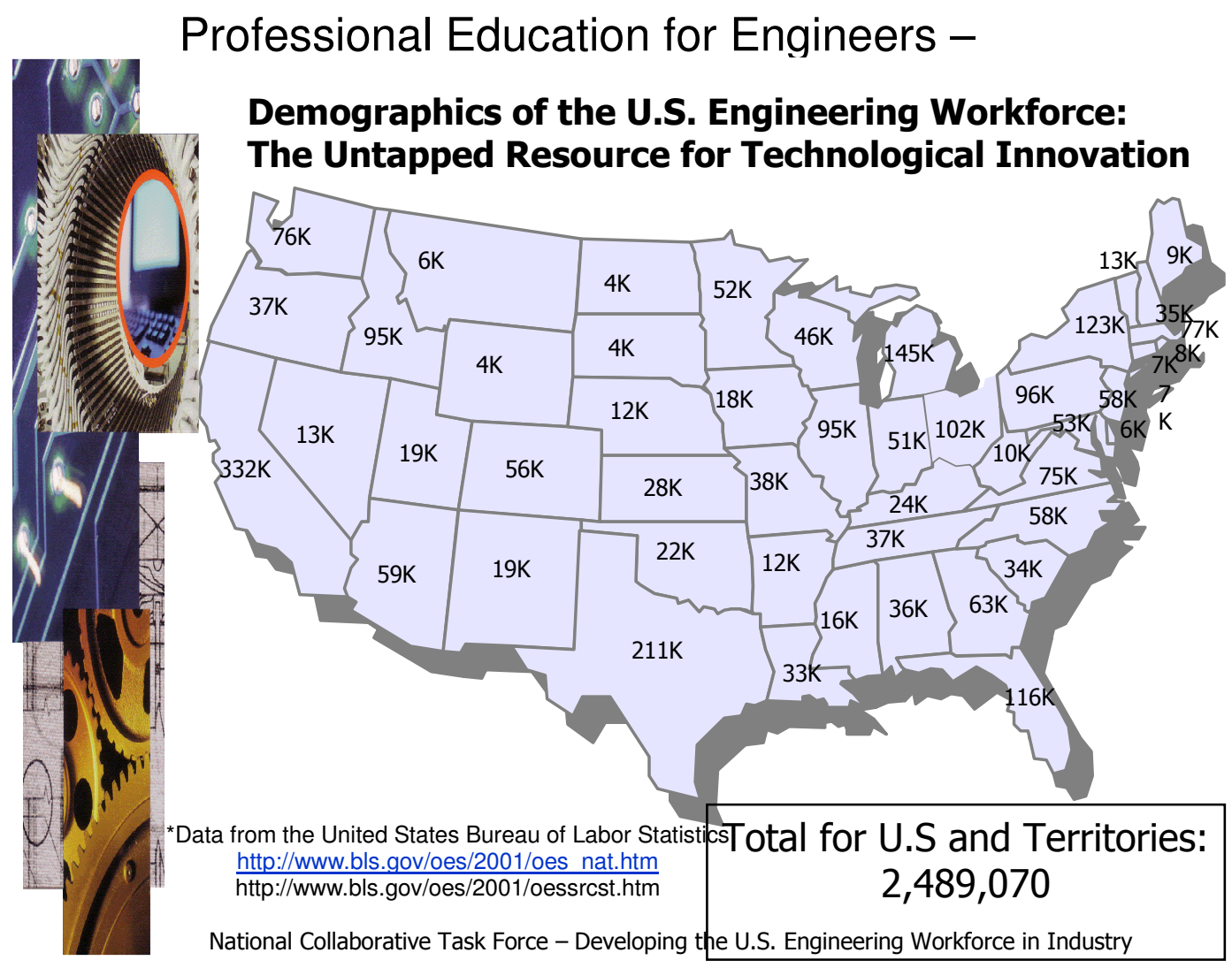

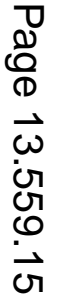




\begin{abstract}
Appendix E
National Collaborative Initiative for Advancement of Professional Engineering Graduate Education for the Nation's Engineers in Industry and Government Service
\end{abstract}

Revitalizing the

U.S. Engineering Workforce for Continuous

Technology Development \& Innovation in Industry

\title{
Our Proposition is Straightforward
}

The National Collaborative Task Force proposes that:

- In the innovation-driven economy, the U.S. engineering workforce is one of our nation's most valuable national resources for creating continuous technological developments and innovations in industry that strengthen our nation's innovative competitiveness for U.S. economic growth and national security

$\square \quad$ One of the best ways to strengthen U.S. innovation, competitiveness and America's economic growth for global leadership is on a regional basis across the country

> By improving our nation's system of professional engineering graduate education to support innovative engineering in America's industry

By clustering innovative graduate centers for professional education around regional industry in all regions and states of the nation that nurture the further creativity, innovative capacity, and leadership abilities of our nation's engineers as an innovation multiplier for competitiveness 


\begin{abstract}
Appendix F
National Collaborative Guidelines for Advancement of Professional Engineering Graduate Education for the Nation's Engineers in Industry and Government Service
\end{abstract}

Revitalizing the

U.S. Engineering Workforce for Continuous

Technology Development \& Innovation in Industry

\title{
Our Guidelines to Accomplish the Task are Attainable
}

The National Collaborative Task Force Guidelines are:

> Focus on innovation and leadership and the development of the U.S. Engineering Workforce for innovative competitiveness in industry, second to none in the world

$>$ Vision -

"Innovation fosters the new ideas, technologies, and processes that lead to better jobs, higher wages and a higher standard of living. For advanced industrial nations no longer able to compete on cost, the capacity to innovate is the most critical element in sustaining competitiveness."

Council on Competitiveness

$>$ Workforce Development -

"The Council's business leaders agree that every company's most important asset are the people who walk in its doors every morning. Talented people creating new ideas and innovative technologies keep the economy strong, and growing stronger. The education and training that spark Americans' creativity and give them cutting-edge skills are a key to competitiveness.

Council on Competitiveness

$>$ Create a new, innovative professional curriculum combined with engineering practice that matches and supports the progressive core-competence skills required for effective engineering leadership of technology development \& innovation in industry - from beginning Entry Level Engineer through Chief Engineer Level for corporate technology responsibility

$>$ Create Graduate centers that will be "statewide clusters" for advanced professional education for engineering innovation and leadership in all 50 states across the nation 


\section{Appendix G}

\section{National Collaborative Project Plan \& Schedule for Advancement of Professional Engineering Graduate Education to Ensure a Strong U.S. Engineering Workforce for Competitiveness}

\section{PROJECT MILESTONES}

The goals, tasks, and action items of the National Collaborative Task Force for Engineering Graduate Education Reform are as follows:

\section{PHASE I - FULL CONCEPT DEVELOPMENT [Years $1 \& 2$ ]}

GOAL 1: To create an innovative model of professional graduate engineering education that is integrative with the practice of engineering, fosters lifelong learning, and enables further growth of engineers beyond entry level in industry for increasing leadership responsibility of technology development $\&$ innovation to ensure U.S. technological leadership for competitiveness and national security purposes

- Define the aims of professional graduate engineering education for the creative practice of engineering

a) "Professional engineering education is no longer viewed as a one time event, but rather as a seamless process that supports continuous growth of creative practitioners throughout their productive careers. Whereas the primary aim of undergraduate engineering education is to prepare students at the basic level for entry Into professional engineering practice... the primary aim of professional graduate education is to provide a coherent educational process at the advanced level that fosters lifelong learning in combination with advanced engineering practice to enrich the practitioner's further growth and skills-set development beyond entrylevel and enable experienced professionals in industry to attain their fullest creative, innovative, and leadership potentials for increasingly responsible roles in creative engineering practice for leadership of technology development \& innovation."

b) "It is expected that during this career-long process of further advanced professional education, intellectual development, and professional growth that the experienced engineering practitioner is not only growing as a continuous student of engineering but is also growing as a creative innovator, leader, and a contributor to the advancement of engineering practice itself through his or her meaningful creative engineering works in industry or government service."

- Define the modern paradigm of the practice of engineering for continuous and systematic innovation

- Define the nine levels of progressive responsibilities and growth in engineering beyond entry [NSPE / ASCE

- Create a new innovative model of professional graduate engineering education for U.S. engineers in industry and government service that enables their further positive growth for leadership of creative engineering works, and supports the manner by which creative professionals learn, grow, and develop in creative practice - from entry level through chief/ vice president engineer level of corporate responsibility and policy making 


\section{PROJECT MILESTONES PHASE I (Continued)}

- Define the progressive innovation abilities, responsibilities, core attributes, and qualifications required of engineers and engineering leaders for responsible leadership of technology development \& innovation and creative engineering works for all levels of Engineering I - IX

$>$ Early career development - From Level I to Level IV Engineer (professional Master of Engineering M.Eng. at Engineer Level IV)

$>$ Middle career development - From Level IV to Level VI Engineer (professional Doctor of Engineering D.Eng. at Engineer Level VI)

$>$ Senior career development - From Level VI to Level IX Engineer (professional Engineering Fellow F.Eng. at Engineer Level VII-IX)

- Define a coherent, sequential framework of integrative professional graduate education combined with engineering practice for all levels of engineering

$>$ Leading to the professional Master of Engineering (M.Eng.) at Level IV

$>$ Leading to the professional Doctor of Engineering (D.Eng.) at Level VI

$>$ Leading to the professional Fellow of Engineering (F.Eng.) Level VII - IX

- Define and align coherent, sequential professional graduate curricula that are integrative with the practice of engineering and that match and support the progressive qualifications, innovative, and leadership abilities required of engineers at every level of engineering responsibility in industry

D Early career development - From Level I to Level IV Engineer (professional Master of Engineering M.Eng. at Engineer Level IV)

$>$ Middle career development - From Level IV to Level VI Engineer (professional Doctor of Engineering D.Eng. at Engineer Level VI)

$>$ Senior career development - From Level VI to Level IX Engineer (professional Engineering Fellow F.Eng. at Engineer Level VII-IX)

- Create and align the process of professional graduate engineering education to be supportive and integrative with the creative practice of engineering for technology development $\&$ innovation [or performance of other creative engineering works] to enable the practitioner's further growth, and to support his or her further graduate development for increasing, progressive responsibilities, core attributes, skills and abilities required at every level of engineering leadership responsibility for technology innovation

a) Focus on a 'learner-centered' approach

b) Focus on creating an educational process that supports practice-centered, and innovation-based [projectbased learning and creativity] and the manner by which experienced practitioners approach real-world [ill- defined projects] and bring forth effective solutions through learning, professional reflection, and creativity as highly skilled practitioners

c) Focus on creating an innovative model of professional graduate education for lifelong learning that develops the further growth of the beginning entry-level graduate from novice, to competent professional, to expert professional, to expert leader in engineering for creative problem-solving and engineering leadership of technical projects, technical programs, and technology policy 


\section{PROJECT MILESTONES PHASE I (Continued)}

d) Focus on incorporating an engagement theory of high-quality programs for graduate education.

"By defining high-quality programs as those that contribute to enriching learning experiences for students in ways that positively affect their growth and development, the theory focuses on a simple by compelling definition: one that emphasizes student learning and development as the primary purpose of higher learning. In so doing, the theory builds upon an increasingly shared view that the development of student talents and abilities is the core of higher education [Conrad - Council of Graduate Schools Report]."

e) Focus on incorporating the known attributes of 'best practice' of high-quality professional graduate education that enable further positive growth and development of experienced working professionals [Conrad Report-Council of Graduate Schools Report]

1) Diverse and experienced faculty / students (working professionals) engaged in practice

2) Participatory cultures and shared program direction in professional graduate education

3) Interactive teaching and learner-centered professional graduate education

4) Connected program requirements of advanced studies, experience, and tangible product

5) Residency in engineering practice component in context of technology development \& Innovation

6) Adequate resources for faculty, students, and program administrative infrastructure

f) Focus on incorporating experiential learning and self-directed learning as synergistic components of advanced professional studies through actual engagement in the practice of engineering for creative technology development \& innovation

g) Focus on sustaining relevancy of the overall system of the professional graduate programs and educational processes to be continuously relevant to the growth needs of the practitioner-student and in nurturing his or her intrinsic creative potential for creative technology development \& innovation projects directly relevant to meaningful industry or societal needs using the systematic engineering method and modern paradigm of the practice of engineering for purposeful innovation 


\section{PROJECT MILESTONES PHASE II}

\section{PHASE II - FULL CONCEPT IMPLEMENTATION [Years 3 \& 4 ]}

GOAL 2: To establish innovative Graduate Centers for Advanced Studies in Engineering Leadership, Technology Innovation, and Policy as a National Demonstration Project for pilot implementation across the country

- Implement the National Demonstration Project as a major initiative across the United States by

- Establish innovative Graduate Centers as regional clusters for professional engineering education for innovation in strong partnership with regional industry and the practicing engineering profession

- Develop model documentation to be shared among National Collaborative universities for establishing Graduate Centers for Advanced Engineering Studies in Technology Development, Innovation and Policy

1) Name of the Center

2) Director(s) including contact information

3) Administrative contact(s) and office locations office locations

4) Mission of Center suitable for publicizing on the University web site

5) Colleges, schools, departments involved

6) List of participating faculty

7) Line of reporting and governance plan

8) How the Center will be funded

9) What will be expected funding levels from internal (cost share, release time, in-kind support etc.)

10) and external sources

11) Required documentation of necessary approvals

- Prepare specific documentation required for approval at each University citing importance and need for professional engineering graduate education to support technology innovation in regional industry for continuous economic development and enhancement of U.S. competitiveness

1) Define the distinctiveness of professional graduate education for creative engineering practice for the creative development and innovation of technology from that of research-based graduate education for scientific discovery

2) Define the mission of the professional graduate programs as being within the mission, scope, and purpose of the university for professional education and engagement with industry

3) Define resources and facilities that are required or for the most part are already in place

4) Define the program champion(s) and core faculty already in place within the university system

5) Define the distinguished adjunct faculty already in place within regional industry

6) Define increased tuition revenues which will result from implementation of professional graduate

7) education to meet the development needs of the regional U.S. engineering workforce in industry

8) Define the benefits and opportunities of enhanced engagement with regional industry, and the benefits of enhanced national \& international recognition that will occur to the university

- Define a five year plan to establish the reputation of the professional graduate program as a model program ranking among the top 10 leading programs in the nation as part of the National Project initiative to enable a strong U.S. Engineering Workforce for competitiveness

1) Prepare supporting documentation to initiate the professional Master of Engineering

2) Prepare supporting documentation to initiate the professional Doctor of Engineering

3) Prepare supporting documentation to initiate the professional Fellow of Engineering 


\section{PROJECT MILESTONES PHASE II (Continued)}

- Establish a strong Industry Advisory Council for advocacy at each Graduate Center

1) Recruit a strong Industry Advisory Council of distinguished stakeholders from regional industry, business and local / state government for advocacy at each Graduate Center who will protect and nurture the mission, purpose, and growth of the Graduate Center as a model in the nation for economic competitiveness and national security purposes

2) Develop and share a model of 'best practice' with all Graduate Centers of the National Collaborative

- Recruit and develop a strong experienced, multidisciplinary professional faculty of innovators, leaders and practitioner scholars from within the total university system and from distinguished adjunct faculty within regional industry

1) Core Faculty - Identify and form a distinguished, professionally oriented core faculty from within the total university system who are tenured and who can teach in this type of unique program for advanced engineering practice, technology innovation and policy studies

2) Adjunct Faculty from Industry - Identify and form a distinguished adjunct faculty of high-caliber engineers from regional industry who are experienced technical experts and or distinguished engineering leaders who can teach in this unique program for advanced engineering practice, technology innovation and policy studies

- Faculty Development- Implement Faculty Development Workshops \& Seminars for professionally oriented core faculty and visiting faculty from industry to embed attributes of high-quality professional graduate education for creative engineering practice, technology innovation, and its leadership

1) Conduct workshop-seminars on mentoring and interactive learning approaches for professionals

2) Conduct workshop-seminars on competency based learning approaches for working professionals

3) Conduct workshop-seminars on organizational cultures for collaborative creativity \& innovation

4) Fund core faculty during summer months to develop professional course / modules /seminars

- Begin to develop in an orderly and sequential manner for program readiness a progressive sequence of advanced professional graduate core courses / modules / seminars for all levels of engineering

1) Early career development - From Level I to Level IV Engineer (leading to professional Master of Engineering M.Eng. at Engineer Level IV)

2) Middle career development - From Level IV to Level VI Engineer (leading to professional Doctor of Engineering D.Eng. at Engineer Level VI)

3) Senior career development - From Level VI to Level IX Engineer (leading to professional Engineering Fellow F.Eng. at Engineer Level VII-IX)

- Recruit an experienced practitioner-student body of high-caliber experienced practicing engineers and engineering leaders from industry or mission oriented government agencies who are employed full-time, and are growing as technology leaders, within regional technology-based industry [Goal: build-up to 100 professionally oriented students (experienced engineers) for steady state over four years]

1) $1^{\text {st }}$ year: Recruit initial graduate cadre of 25 experienced professionals from industry

2) $2^{\text {nd }}$ year: Recruit additional new cadre of 25 experienced professionals from industry

3) $3^{\text {rd }}$ year: Recruit additional new cadre of 25 experienced professionals from industry

4) $4^{\text {th }}$ year: Recruit additional new cadre of 25 experienced professionals from industry 


\section{PROJECT MILESTONES PHASE II (Continued)}

- Initiate start-up of a critical mass of 5-10 innovative universities in different states working in collaborative participation with the practicing profession in industry

1) Use a systems approach under the guidance of a National Project office to grow all innovative Graduate Centers using a collaborative plan for implementation, continuous improvement and shared best practice

2) Build on the formidable strengths of a combined teaching faculty from regional universities and from engineering experts in regional industry across the nation; combined with the strengths of an experienced student body of practitioners who are growing as innovators and engineering leaders at the cutting edge of technology development to sustain U.S. preeminence

3) Build on the silent successes / attributes of high-quality programs for working professionals which have been already proven across the United States [Conrad - Council of Graduate Schools]

4) Build the Graduate Centers in partnership with regional industry and the practicing profession in engineering for success and continuous improvement

- Initiate the founding and development of the mainstay components of the Graduate Centers

$\square \quad$ Advanced Studies in Engineering Leadership, Technology Innovation \& Policy. To serve as innovative graduate centers of high-quality professional engineering graduate education by establishing, developing and implementing coherent programs of professionally-oriented, innovation-centered engineering graduate education through the professional spectrum of M.Eng., Eng.D., and Fellow levels of advanced practice for engineers and engineering leaders within their respective regional industries.

$\square \quad$ Advanced Technology Development Laboratory for Innovation [Invention Factory]. To serve as a working environment that fosters professional creative scholarship and advanced development in the practice of engineering for innovation by establishing, developing, and implementing a 'teaching laboratory' for advanced engineering development [responsive to meaningful real-world industrial / societal needs] that serves to develop the creative engineering scholarship of center faculty for faculty development and that of promising undergraduate engineering students during the summers.

Whereas NSF has successfully created and implemented Research Experiences for Undergraduates (REU) on university campuses across the nation, we can do in a similar manner through the National Collaborative to create and implement Technology Development- Innovation Experiences for Undergraduates (TDEU) as a training ground and recruitment resource to sustain the nation's pipeline of 'creative engineering talent' for industry. The TDEU program will provide promising undergraduates the opportunity to conduct meaningful technology development \& innovation under the guidance and mentorship of core center faculty members and distinguished, experienced visiting faculty from regional industry.

$\square \quad$ Annual Distinguished Lecture Series in the Practice of Engineering and its Leadership. To serve as a platform for motivation, encouragement, and inspiration in the practice of engineering by establishing, developing, and implementing an annual distinguished lecture series that sustains the 'spirit and intent' of the graduate center in the advancement of the practice of engineering and its leadership in meaningful creative work though invited addresses by distinguished engineers from industry, government service, or private practice with sponsors, friends, faculty, and students of the center.

- Implement Roll-Out of Model Programs at 5-10 Graduate Centers across the Nation 


\section{PROJECT MILESTONES PHASE III}

\section{PHASE III - FULL CONCEPT IMPROVEMENT \& SUSTAINABILITY [Year 5 ]}

GOAL 3: To assess needs for continuous operational improvement; and to continuously upgrade professional graduate education programs at all levels, the educational processes, the development of faculty, the organizational infrastructure for innovation, and relations with industry to meet these needs.

- Assess regional needs of the practitioner-student body for innovation, the needs of faculty, the organizational infrastructure, and operations to continuously upgrade professional graduate education programs at all levels, the educational processes, the development of faculty, the organizational infrastructure for innovation, and continuously enhance relations with industry to meet these needs.

- Build constancy of purpose for continuous quality improvement, growth and sustainability into mainstream operations at all Graduate Centers across the United States from the earliest stages of start-up of the project

1) Internalize and adopt philosophy of continuous improvement, development, and innovation at all regional Graduate Centers

2) Build culture of creative collaboration within the National Collaborative itself that is open to the addition of new industry and of other universities to the National Collaborative as appropriate in affecting the positive growth and long-term success of the initiative's mission and purpose

3) Build sustaining organizational cultures at all regional graduate centers where lifelong learning, creativity and innovation flourishes

4) Build strong engagement with the regional U.S. engineering workforce in industry in all parts of the United States working with the National Collaborative in this major advancement

5) Build graduate cultures for innovation upon the attributes of collaborative learning, collaborative creativity, and engagement theory that enable continuous growth of engineers and engineering leaders creative working professionals

6) Build an interactive teaching and learning culture among faculty and practitioner-participants that engages collaborative learning, creativity, innovation, and teamwork in meaningful engineering works

7) Build a collaborative culture for continuous improvement, innovation, and trust that develops faculty and students as collaborative creative professionals where continuous improvement and innovation is the measured constant at the individual / team level of professional responsibility

- Develop methodology to assess and improve the overall program from a systems perspective

1) Develop methodology to assess growth needs of graduate engineers within regional industry and to maintain program relevancy to the growth needs and innovation skills of engineers across the U.S.

2) Develop methodology to foster continuous faculty development and scholarship year long

3) Develop methodology to assess practitioner growth through competency-based learning criteria for the planned graduate studies component

4) Develop methodology to assess progress of directed technology development projects relevant to specific needs of Industry / general betterment of society

5) Develop methodology to assess worth of directed technology development projects to industry

6) Develop methodology to assess impact / economic multiplier of graduate centers to Region / Nation

7) Develop methodology to assure financial sustainability of all graduate centers to achieve their mission throughout the years to enhance the innovative capacity of the U.S. engineering workforce in industry to ensure U.S. economic competitiveness and national security 


\section{PROJECT MILESTONES PHASE III (Continued)}

- Develop new Professional Electives / Modules / Seminars as required specific to needs of practicing engineers and engineering leaders within regional industry of Graduate Centers

1) Assess specific elective needs of engineers in regional industry

2) Identify courses already operational across the U.S. that are available to meet these needs

3) Develop new course electives directly responsive to specific needs of engineers in regional industry

- Conceive and implement a new model of relevant Faculty Reward System Reform for professionally-oriented core faculty at Graduate Centers

1) Define importance of Faculty Reward System Reform in order to deliberately advance and sustain professional engineering graduate education for the U.S. engineering workforce in industry

2) Define urgency to advance professional engineering education for the practicing profession to enhance the innovative capacity of U.S. engineering workforce for competitiveness and national security purposes

3) Define major issues driving faculty reward system reform to sustain the advancement of professional engineering graduate education across the United States

4) Identify major issues required for recruitment of professionally oriented faculty to attain excellence in high-quality professional engineering graduate education for practice

1) Identify the current incongruities of using unit criteria to assess growth in basic research for investigation / discovery to gain a better understanding of phenomena from that to assess growth in engineering practice for purposive creative engineering development and innovation of technology to meet real-world societal / industrial needs for advancement and betterment of human welfare

- Identify typical Professional Faculty Reward Criteria used in other Practice Oriented Professions

1) Identify professionally oriented faculty reward criteria used in other practice oriented professions (such as law schools)

2) Identify professional criteria used to assess promotion levels in engineering in industry government service for leadership of the systematic development of innovative technology responsive to real needs

3) Identify unit criteria reform underway at various schools of engineering across the United States

- Create a New Model Template of Unit Criteria for Professionally-Oriented Faculty that fosters excellence in professional engineering graduate education, professional scholarship, and engagement in advance engineering practice for leadership of technology development \& innovation

1) Define characteristics of professional engineering scholarship that differentiate creative engineering practice for technology development, innovation, and its leadership from scholarship of academic basic research for investigation / discovery to gain a better understanding of phenomena

2) Create new unit criteria as a model template of best practice for professional scholarship, teaching, and engagement that nurtures professional growth and reward for core / adjunct professionally oriented faculty

3) Share model best practice unit criteria for internalization / implementation at all Graduate Centers

4) Implement best practice unit criteria into mainstream operations at all Graduate Centers as a mainstay of the National Demonstration Project 


\section{PROJECT MILESTONES PHASE III (Continued)}

- Develop a new model for financial sustainability of professionally-oriented engineering graduate education for practice that grows and sustains the Graduate Centers over the long-term

1) Create a new financial model for sustainability of innovative Professional Engineering Graduate Education in collaboration with industry and government stakeholders that fosters the advancement of professional graduate education for the U.S. engineering workforce in industry and unlocks intrinsic human potential for purposeful creativity, innovation and responsible leadership to ensure future U.S. technology competitiveness

2) Survey funding mechanisms of other types of professional schools [such as high-quality law schools]

3) Create or pattern new types of funding mechanisms ( e.g. law schools ) to ensure sustainability of highquality professional engineering graduate programs to enable a strong U.S. Engineering Workforce for competitiveness employing a combination of the following -

口 Tuition

口 Industry partnership

State/ Federal Government partnership

口 Endowments and gifts of Graduate Centers 


\section{PHASE IV - FULL CONCEPT TRANSFER \& REPLICATION ACROSS THE UNITED STATES}

GOAL 4: To replicate the innovative Graduate Centers in all 50 states across the country in order to accelerate the development of the U.S. engineering workforce for U.S. preeminence in technological innovation to enhance economic competitiveness and national security using the combined formidable strengths of industry and regional universities that will be second to none

- Share 'Best Practice' of the National Collaborative across the United States

- Replicate the National Demonstration Project in each state across the United States

- Grow five Graduate Centers per year over 10 years across the United States until all 50 states have enhanced educational and innovative capability of high-quality advanced professional engineering education for technology innovation and leadership for the practicing profession in their regional industry; and regional industry has an increased core competence and culture for continuous and systematic technology development \& innovation for global competitiveness and national security purposes

- Year 0: Launch of National Demonstration Project Initiative [original start-up coalition of 5 -10 universities]

- By year 5: Full operations of 5-10 Graduate Centers up and running in 5-10 different states

- By year 6: Total of 10 Graduate Centers in 10 states @ 1000 engineers working on 1000 innovations

- By year 7: Total of 15 Graduate Centers in 15 states @ 1500 engineers working on 1500 innovations

- By year 8: Total of 20 Graduate Centers in 20 states @ 2000 engineers working on 2000 innovations

- By year 9: Total of 25 Graduate Centers in 25 states @ 2500 engineers working on 2500 innovations

- By year 10: Total of 30 Graduate Centers in 30 states @ 3000 engineers working on 3000 innovations

- By year 11: Total of 35 Graduate Centers in 35 states @ 3500 engineers working on 3500 innovations

- By year 12: Total of 40 Graduate Centers in 40 states @ 4000 engineers working on 4000 innovations

- By year 13: Total of 45 Graduate Centers in 45 states @ 4500 engineers working on 4500 innovations

- By year 14: Total of 50 Graduate Centers in 50 states @ 5000 engineers working on 5000 innovations 